\title{
Escola e família no jornal O Arquidiocesano de Mariana (1959-1991): "Defenderá ele os direitos de Deus e da comunidade cristã"1
}

\section{School and family in the Mariana's newspaper O Arquidiocesano (1959-1991): "He will defend the rights of God and the Christian community"}

\author{
Fernanda A. O. Rodrigues Silva* \\ Rosana Areal de Carvalho*
}

\begin{abstract}
RESUMO
O semanário O Arquidiocesano, periódico da Arquidiocese de Mariana (MG), circulou entre 1959 e 1991 com tiragem anual de 6.000 exemplares. Dos objetivos do jornal constam o de "cuidar da vida religiosa das Paróquias". O periódico adentrou os campos sociais incluindo a escola. É possível perceber a educação como tema recorrente no que tange à formação cristã como a preocupação com a chegada da televisão no interior dos lares e a campanha contra o comunismo. De 1962 a 1989 somam-se 61 artigos com o tema "escola", que passa a ser objeto de análise, sobretudo no que concerne à presença da fé católica no sistema público. Os artigos foram assinados por membros da hierarquia da Igreja e paroquianos convidados. O corpus de pesquisa são as edições que tratam da educação escolar. Selecionamos os artigos que abordam a escola e a família e destacamos a visão da igreja sobre a instituição escolar como colaboradora na formação humana consoante à difusão dos princípios cristãos. Se o futuro da criança é cristão, faz sentido a escolha dos pais pela escola católica guiada pela professora na mesma fé. Fica clara a equação: família cristã é igual a escola cristã. Podemos finalizar
\end{abstract}

$1 \mathrm{O}$ tema foi apresentado, em versão inicial, na III Jornadas de la Prensa Pedagógica, Salamanca, 2018.

${ }^{*}$ Universidade Federal de Ouro Preto. Ouro Preto, Minas Gerais, Brasil. E-mail: fernandasilva@ufop.edu.br - https://orcid.org/0000-0002-8790-0882 E-mail: rosanareal@ufop. edu.br - https://orcid.org/0000-0002-0114-4239 
com a assertiva de que $O$ Arquidiocesano vela pela população católica para além do espaço físico das igrejas ou dos sermões por meio do controle da tríade família, escola e professora.

Palavras-chave: Educação católica. Imprensa católica. História da educação. Família. Escola primária.

\begin{abstract}
The weekly O Arquidiocesano, a periodical from the Archdiocese of Mariana (MG), circulated between 1959 and 1991, with an annual circulation of 6,000 copies. One of the newspaper's goals includes "taking care of the religious life of the Parishes." The periodical entered the social fields, including the school. It is possible to perceive education as a recurring theme about Christian education, such as the concern with the arrival of television in the homes and the campaign against communism. From 1962 to 1989, the journal added 61 articles with the school theme, which turns to be an analysis object, especially concerning the Catholic faith's presence in the public system. The church's hierarchy members and invited parishioners signed most of the items. The research corpus is editions that deal with school education. We selected articles that address the school and the family and highligted the church's view of the school as a collaborator in human form, according to the spread of Christian principles. If the child's future is Christian, it makes sense for the parents to choose the Catholic school guided by the teacher in the same faith. The equation is explicit: Christian family is like a Christian school. We can end with the statement that affirms that $\mathrm{O}$ Arquidiocesano watches over the Catholic population beyond churches' physical space or sermons through the control of the family, school, and teacher triad.

Keywords: Catholic education. Catholic press. History of Education. Family. Primary School.
\end{abstract}

\title{
Imprensa como fonte e objeto
}

O conhecimento histórico inscreve-se em tempo e espaço determinados e a matéria prima, qualquer que seja o objeto ou a abordagem, é a fonte. A importância das fontes para a produção do conhecimento histórico pode ser apreciada em todas as correntes historiográficas e estas se diferem entre si, dentre outros aspectos, pela compreensão em torno do que são fontes para a história e o que é um documento histórico. A História como resultado de uma prática 
investigativa em busca de respostas para os problemas, os questionamentos e os debates postos no presente, ou a história problema como defendida pela Escola dos Annales, tem sido a matriz mais usual desde as últimas décadas do século XX.

A produção historiográfica, ao longo do tempo, foi comprovando ser o objeto, ou objetivos, ou os problemas a serem respondidos, o ponto fulcral para a escolha das fontes. A ampliação do conceito de documento também foi acompanhada pela crítica documental; desmascarando a categoria de verdade atribuída às fontes oficiais, como a legislação, por exemplo. Tudo isso acompanhado de novas tendências historiográficas, posto que os problemas do presente exigiam do historiador novo arcabouço epistemológico.

E não poderia ser diferente na história da educação que, a partir dos anos de 1980, acolheu avidamente as alterações ocorridas no campo historiográfico. Tal movimento impingiu desenvolvimento qualitativo e quantitativo na produção da área, muito bem expresso nas dissertações, teses, eventos e grupos de pesquisa. Para Carlos Eduardo Vieira,

O alargamento temático para os pensares, os saberes, as práticas, os processos, as pedagogias, os agentes, as instituições demandou investimento teórico dos pesquisadores no intuito de ampliar o conceito de documento, bem como levantar, catalogar e disponibilizar esses acervos (VIEIRA, 2007, p. 12).

Nessa toada, foi resgatada a imprensa periódica, especializada ou mesmo de entretenimento, como fonte e objeto. Fonte esta que tem ocupado um espaço significativo na produção historiográfica e na história da educação. Como imprensa periódica entendemos os impressos com noticiário diversificado, com periodicidade regular, na maioria das vezes diária; e os impressos de entretenimento, também conhecidos como revistas, destinados, como o próprio nome diz, a entreter seu público leitor com variedades, incluindo indicações culturais, receitas domésticas, reportagens de cunho geral etc.

Entende-se por imprensa especializada a imprensa pedagógica-produzida por e para professores, alunos e demais sujeitos diretamente vinculados ao campo. Como sintetiza Maria Helena Câmara Bastos (2002), essa imprensa, enquanto dispositivo social, opera na orientação intelectual e moral da formação de professores. Em outros casos, trata-se da formação discente, como o são os jornais acadêmicos das escolas de Direito no Brasil desenvolvidos a partir do trabalho de Sérgio Adorno (1988). 
Ao se tratar de uma concepção ampla de educação ou de práticas pedagógicas, ou seja, se se verificar a pedagogia com abrangência para além dos muros escolares, não será difícil confirmar a imprensa como um "dos dispositivos privilegiados para forjar o sujeito/cidadão" (BASTOS, 2002, p. 151). Entretanto, não por acaso era a imprensa considerada como fonte suspeita, permeada por posicionamentos enviesados e interesseiros. Também por isso, em um artigo de 1945, Venâncio Filho, ao tratar das fontes para a história da educação, alertava para a riqueza e os perigos da imprensa periódica como fonte:

Os jornais e os periódicos podem igualmente fornecer dados preciosos, indicando rumos de investigações, esclarecendo dúvidas, sugerindo problemas, às vezes insolúveis. É certo que se deve submetê-los a rigorosa crítica histórica, precavendo-se contra o prestígio místico de jornais antigos, a cujos informes a idade dá tanto relevo (VENÂNCIO FILHO, 1945, p. 372).

Trabalho exemplar, inovador e polêmico para a época em que foi produzido, é “Ordem e Progresso”, de Gilberto Freyre (2013), publicado no ano de 1957. O autor retirou dos jornais, mais especificamente dos anúncios comerciais, os dados utilizados para explicar a desestruturação da sociedade patriarcal brasileira sustentada no trabalho escravo como consequência da instituição do trabalho livre.

Os trabalhos de Maria Helena Câmara Bastos, especialmente os que tratam da imprensa produzida pelo Centro dos Professores do Estado do Rio Grande do Sul/Sindicato dos Trabalhadores da Educação (CPERS/Sindicato), despertaram a atenção dos pesquisadores da história da educação para esse leque de fontes produzidos pelo CPERS. De igual riqueza são os trabalhos que tiveram como fonte o periódico oficial, por exemplo, a tese de doutorado de Maurilane Biccas (2008), cujo objeto protagonista foi a Revista do Ensino publicada pela Secretaria Estadual de Educação de Minas Gerais, entre 1925 e 1971.

A pesquisa que temos desenvolvido se espelha, e se inspira, nesses tantos outros trabalhos, tomando como fonte um periódico semanal, porta-voz da Arquidiocese de Mariana, O Arquidiocesano, publicado entre 1959 e 1991. As edições deste periódico, apesar de não ter como público alvo o escolar, nem por isso deixou de carrear em suas páginas uma proposta pedagógica e um conceito de educação. Segundo Bastos, esse tipo de imprensa dissemina a formação de um sujeito na medida em que "constitui verdades", "divulga saberes" e "é portadora e produtora de significações” (BASTOS, 2002, p. 152). 
Ainda que pouco investigado no âmbito da história da educação, $O$ Arquidiocesano vem sendo analisado como fonte para trabalhos cujos objetos situam-se no período da ditadura civil-militar no Brasil, nas décadas de 1960 e 1970. O estudo de Gabriela Pereira da Cunha Lima (2011) se valeu do jornal para perfilar a postura da Igreja Católica nos "anos de chumbo" e o de Raquel Evangelista de Jesus (2018) trabalhou com a posição do periódico no tocante ao ensino da disciplina Educação Moral e Cívica no âmbito escolar. Essas duas incursões anunciaram a riqueza documental do periódico, despertando a atenção de outros pesquisadores.

As relações entre Igreja, família e escola são pano de fundo deste artigo, retratados no semanário católico $O$ Arquidiocesano no que se refere à circulação de ideias e ideais. Elencamos aspectos dessa tríade para um estudo mais detido, tomando a escola como espaço privilegiado de disseminação de conhecimentos e valores, a Igreja como controladora da fé da sociedade e a família como caixa de ressonância do que era tratado tanto na escola quanto na Igreja. No centro da tríade está o/a professor/a no papel de transmissor e instrumento de manutenção da fé católica.

\section{Paróquia e sociedade unidas pela fé nas páginas de $\boldsymbol{O}$ Arquidiocesano}

O jornal O Arquidiocesano, iniciativa da Arquidiocese de Mariana-MG, nasceu como instrumento oficial da imprensa católica em 1959. Entre os anos de 1959 e 1991 circulou, semanalmente, nas cidades mineiras de Mariana, Viçosa, Ouro Preto, Dionísio, Itabira, Barra Longa e João Monlevade, oficialmente. Em 1992 foi renomeado como O Pastoral, e segue nos dias de hoje em circulação. Como porta-voz da Arquidiocese de Mariana, alcançou uma tiragem média de 6.000 exemplares no período. O acervo completo do jornal pode ser encontrado no Seminário São José e no Arquivo Eclesiástico da Arquidiocese de Mariana, ambos em Mariana-MG, onde encontram-se bem acondicionados e abertos ao público. Na Hemeroteca da Biblioteca Nacional encontram-se digitalizados alguns poucos números.

Como informa o Expediente (Figura 1), o jornal era o órgão oficial da Arquidiocese, sob a orientação do Arcebispo Coadjutor Dom Oscar de Oliveira. Em 1960, Dom Oscar passou a ocupar a posição de Arcebispo após o falecimento de Dom Helvécio Gomes de Oliveira. Ainda no Expediente, observa-se que a assinatura do benfeitor era a mais elevada, indicando o compromisso dos paroquianos em manter o jornal e o entendimento da importância deste para a comunidade. Também informa acerca dos colaboradores, dentre eles o clero da Arquidiocese. 
FIGURA 1 - EXPEDIENTE DE O ARQUIDIOCESANO

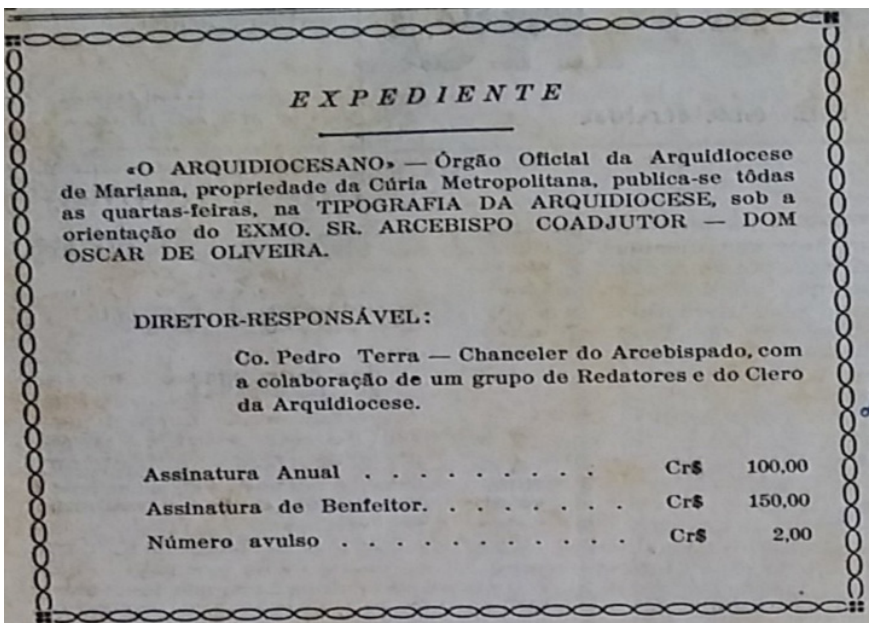

FONTE: O Arquidiocesano, 1959.

Em Razão Dêste Jornal (Figura 2), editorial do primeiro número, afirmam que "Pelo nosso jornal interar-se-ão Clero e Fiéis dos Decretos e escritos do Prelado, dos mais importantes atos da Cúria Metropolitana e da vida espiritual de tôda a Arquidiocese" (OLIVEIRA, 1959, capa). Acrescenta que, sendo o jornal um instrumento de coesão entre Igreja e fiéis, não tem filiação política e presta-se à defesa de Deus e da comunidade cristã.

FIGURA 2 - EXCERTO DA MATÉRIA RAZÃO DÊSTE JORNAL - DOM OSCAR DE OLIVEIRA (ARCEBISPO COADJUTOR)

Terá ainda por escopo o nosso semanário, levar às almas o conhecimento da doutrina social da Santa Igreja: defenderá êle os direitos de Deus e da Comunidade cristâ, com absoluta isenção e independência de partidarismos políticos, pois nossa Politica é o Evangelho.

Firmeza na exposição da doutrina da Igreja, unida d̀ serenidade da caridade cristä, há de ser o lema de "O ARQUIDIOCESANO".

FONTE: O Arquidiocesano, 1959. 
Com o objetivo de cuidar da vida religiosa das Paróquias, o periódico adentrou os campos sociais incluindo a escola. Ao longo das edições é possível perceber a educação como tema recorrente no que tange à formação cristã, como expressa Dom Oscar de Oliveira em Educação da Juventude (OLIVEIRA, 1963, p. 4). A matéria reafirma o cuidado necessário com o ensino do catecismo e com a formação religiosa das crianças, dos adolescentes e dos jovens, bem como a preocupação com a chegada da televisão no interior dos lares e a presença do comunismo na sociedade.

Gabriela Pereira da Cunha Lima (2011), em Educação nos tempos de chumbo: uma visão do pensamento conservador católico através das páginas do jornal $O$ Arquidiocesano, explorou as intenções de educação moral, ou seja, condutas, comportamentos, usos que, sob a orientação da Igreja Católica, pudessem corromper a moral cristã. A televisão, o comunismo (Figura 3), os vestuários, a educação sexual e os movimentos populares, dentre outros, são temas abordados pelo discurso católico de forma conservadora.

Parte da missão religiosa do jornal se concretiza no fato de os artigos serem assinados por membros da hierarquia da Igreja ou por paroquianos convidados. Por exemplo, na matéria sobre a ameaça do comunismo no país, assinada pelo Pe. Belchior Cornélio da Silva (1959), percebe-se que a posição do prelado reforça e reflete alinhamento aos preceitos da Santa Sé. Ainda na mesma métrica, de preservar o tom evangelizador, por vezes reproduziam artigos publicados em outros jornais católicos.

\section{COMUEISMO EM 3 TEMPOS Pe. Belchior Cornélio da Silva. C. (02.}

Razão tem o Papa de continuar alertando o mundo em face do perigo comunista. A possibilidade de mais frequente comunicação entre o mundo ocidentaI e os países comunistas, certas táticas usadas ùltimamente pelos dirigentes soviéticos para captar a simpatia das nações livres, tornam mesmo mais necessárias as advertências pontifícias. Consideremos três manobras comunistas receutes. Tôdas as três se relacionam com a raalidade brasileira.

FONTE: O Arquidiocesano, 1959. 
Ao se verificar a linha do jornal interessa-nos compreender as visões de escola e família sob o manto da Igreja. Para tanto, o corpus desta pesquisa são as edições que tratam da educação escolar. Selecionamos os artigos que abordam as disciplinas escolares, as condições materiais e pedagógicas da escola, acrescidos dos seguintes temas: Educação Sexual, Moral e Cívica, Língua Portuguesa, Formação de Professores, Escolarização da população adulta, Ensino Religioso e outros aspectos do processo educativo escolar como a greve dos professores em 1959 e as correntes pedagógicas. Os artigos tiveram seus conteúdos analisados para efeito de categorização nos eixos escola e família.

\section{A presença da escola no semanário episcopal $O$ Arquidiocesano}

Nos três primeiros anos de circulação, o jornal tratou indiretamente de temas relativos à escola. Em $1960 \mathrm{fez}$ referência à liberdade de ensino e no mesmo ano, em outra edição, aludiu ao trâmite da Lei de Diretrizes e Bases no senado que sairia em 1961. As questões referentes à escola começam a partir de 1962 com o poema abaixo A Escola.

FIGURA $4-A$ ESCOLA (POESIA)

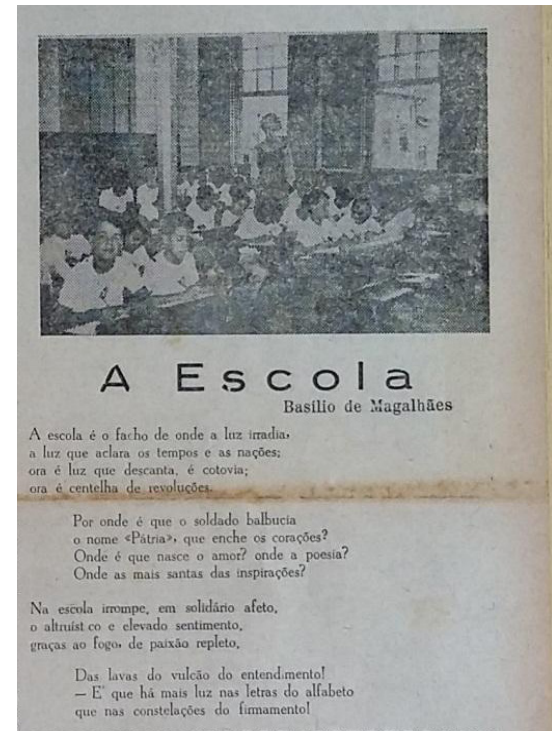

FONTE: O Arquidiocesano, 1962. 
O autor Basílio da Gama Magalhães (1962) enaltece a instituição escolar, o lugar de "onde a luz irradia", luz essa entendida na interseção entre conhecimento e fé, o que a torna objeto de atenção pelo prelado. De 1962 a 1989 somam-se ao longo das edições de $O$ Arquidiocesano 61 artigos com o tema escola, a partir de então, ela passa a ser objeto de análise, sobretudo no que concerne à presença da fé católica no sistema público. A disputa da arquidiocese pela escola pública objetiva conservação e manutenção do catolicismo no âmbito social.

Do ponto de vista da autoria, os artigos encontram-se assim distribuídos: são 44 matérias com autoria de instituições e representantes da própria organização religiosa, das quais 20 são assinadas por bispos, arcebispos, monsenhores, cônegos e padres. Dentre esses 20 artigos oriundos de membros da Igreja Católica, 14 são assinados por Dom Oscar de Oliveira (1919-1977), dirigente máximo da Arquidiocese de Mariana entre os anos de 1960 e 1988. Os 17 escritos restantes estão anônimos e são mencionados como "autor não identificado" (ANI) no quadro a seguir. Tais quantitativos comprovam, por um lado, a linha editorial assumida pelo periódico, qual seja, orientar a conduta religiosa dos leitores e, por outro, dizem do conceito estendido de "vida religiosa das Paróquias" ao aliar escola como extensão da família (OLIVEIRA, 1959, capa). O quadro 1 apresenta um recorte das notícias que abordam os assuntos escola e família.

\section{QUADRO 1 - A ESCOLA E FAMÍLIA NO O ARQUIDIOCESANO (1962-1989)²}

\begin{tabular}{|c|c|c|c|c|c|}
\hline Ed. & Ano & Data & Pág. & $\begin{array}{l}\text { Notícias publicadas com tema } \\
\text { Escola }\end{array}$ & Autor \\
\hline 128 & 1962 & $25 /$ fev & 3 & $\begin{array}{l}\text { Cooperativa de Consumo de } \\
\text { Material Escolar de Mariana, Ltda. } \\
\text { (Edital de } 1^{\mathrm{a}} \text { Convocação) }\end{array}$ & José Maurílio Coelho \\
\hline 146 & 1962 & 01/jul & Capa & A Escola (Poema) & $\begin{array}{l}\text { Basílio da Gama } \\
\text { Magalhães }\end{array}$ \\
\hline 190 & 1963 & 05/mai & 3 & Escolas Radiofônicas (anúncio) & ANI \\
\hline 194 & 1963 & $02 /$ jun & 2 & $\begin{array}{l}\text { Escola de verdade estádio de } \\
\text { Caridade, a ação católica que forma } \\
\text { fiéis firmes e perseverantes }\end{array}$ & ANI \\
\hline 216 & 1963 & $03 /$ nov & 3 & Escola, extensão da família & $\begin{array}{l}\text { Publicação do Diário } \\
\text { de Notícias de Ribeirão } \\
\text { Preto }(31 / 09 / 1961)\end{array}$ \\
\hline 232 & 1964 & $23 / \mathrm{fev}$ & 4 & Escola de Belas Artes em Mariana & ANI \\
\hline 283 & 1965 & $14 / \mathrm{fev}$ & 3 & A criança escolar & Dom Oscar de Oliveira \\
\hline
\end{tabular}

(continua)

2 Os artigos aqui mencionados estão arquivados na Biblioteca do Seminário de São José, em Mariana (MG), e no Arquivo Histórico da Arquidiocese de Mariana. 
(continuação)

\begin{tabular}{|c|c|c|c|c|c|}
\hline Ed. & Ano & Data & Pág. & $\begin{array}{l}\text { Notícias publicadas com tema } \\
\text { Escola }\end{array}$ & Autor \\
\hline 293 & 1965 & $25 / \mathrm{abr}$ & 2 & Escola para formação de catequistas & ANI \\
\hline 328 & 1965 & $26 / \mathrm{dez}$ & 3 & $\begin{array}{l}\text { Ensino Religioso nas Escolas } \\
\text { Oficiais (Decreto/Notícia) }\end{array}$ & ANI \\
\hline 345 & 1966 & $24 / a b r$ & 3 & $\begin{array}{l}\text { Ensino Religioso nas Escolas: } \\
\text { Povo espera }\end{array}$ & ANI \\
\hline 405 & 1967 & 18/jun & 2 & Ensino Religioso nas Escolas & Padre Deolindo Coelho \\
\hline 430 & 1967 & $10 / \mathrm{dez}$ & Capa & $\begin{array}{l}\text { Concílio Vaticano II e Escolas } \\
\text { Católicas }\end{array}$ & Dom Oscar de Oliveira \\
\hline 438 & 1968 & $04 / \mathrm{fev}$ & Capa & Paulo VI e as Escolas Católicas & Dom Oscar de Oliveira \\
\hline 439 & 1968 & $11 / \mathrm{fev}$ & Capa & Paulo VI e as Escolas Católicas (II) & Dom Oscar de Oliveira \\
\hline 440 & 1968 & $18 / \mathrm{fev}$ & Capa & Escolas Católicas (III) & Dom Oscar de Oliveira \\
\hline 441 & 1968 & $25 / \mathrm{fev}$ & Capa & Família, Escola Basilar & Dom Oscar de Oliveira \\
\hline 441 & 1968 & $25 / \mathrm{fev}$ & Capa & Escola Nova & ANI \\
\hline 442 & 1968 & $03 / \mathrm{mar}$ & Capa & Escola e Família & Dom Oscar de Oliveira \\
\hline 442 & 1968 & 03/mar & Capa & A Igreja é uma Escola & $\begin{array}{l}\text { Circular dos Metropolitas } \\
\text { do Brasil, } 1917\end{array}$ \\
\hline 451 & 1968 & $05 / \mathrm{mai}$ & 2 & $\begin{array}{l}\text { Educação... Educação... Educação } \\
\text { (A Escola Católica, um instrumento } \\
\text { a serviço da evangelização...) }\end{array}$ & $\begin{array}{l}\text { Conselho Episcopal } \\
\text { Latino Americano }\end{array}$ \\
\hline 451 & 1968 & $05 / \mathrm{mai}$ & 3 & $\begin{array}{l}\text { Verificação dos Trabalhos escolares } \\
\text { dos filhos }\end{array}$ & Myriam \\
\hline 452 & 1968 & $12 / \mathrm{mai}$ & 3 & O Lar, a primeira escola da vida & Agenor Cattoni \\
\hline 488 & 1969 & 19/jan & Capa & $\begin{array}{l}\text { Às Beneméritas Professoras das } \\
\text { Escolas Primárias }\end{array}$ & Dom Oscar de Oliveira \\
\hline 488 & 1969 & 19/jan & 4 & Escola da Lata de Lixo & ANI \\
\hline 525 & 1969 & 05/out & 4 & Pais e Escola & Ecos Cristóforos \\
\hline 542 & 1970 & $01 / \mathrm{fev}$ & Capa & Em Prol da Escola Primária & Dom Oscar de Oliveira \\
\hline 545 & 1970 & $22 / \mathrm{fev}$ & 4 & $\begin{array}{l}\text { Para as beneméritas Professoras da } \\
\text { Escola Primária }\end{array}$ & ANI \\
\hline 641 & 1971 & $26 / \mathrm{dez}$ & Capa & $\begin{array}{l}\text { Mestre, formador do Homem } \\
\text { (Discurso feito na Colação de grau } \\
\text { da Escola Normal de Barão de } \\
\text { Cocais) }\end{array}$ & Dom Oscar de Oliveira \\
\hline 671 & 1973 & $18 / \mathrm{fev}$ & 3 & $\begin{array}{l}\text { Ainda há lugar para a Escola } \\
\text { católica? }\end{array}$ & O São Paulo \\
\hline 728 & 1973 & 26/ago & 3 & Por que uma escola de Pais? & ANI \\
\hline 771 & 1974 & $23 /$ jun & 3 & $\begin{array}{l}\text { Ensino Religioso nas Escolas } \\
\text { Oficiais (Decreto/Notícia) }\end{array}$ & $\begin{array}{l}\text { Sec. de E. Edu. - Agnelo } \\
\text { Correia Viana }\end{array}$ \\
\hline 843 & 1975 & $09 /$ nov & 3 & $\begin{array}{l}\text { A Igreja, criadora das primeiras } \\
\text { escolas primárias em M. Gerais }\end{array}$ & Dom Oscar de Oliveira \\
\hline
\end{tabular}

(continua) 
SILA, F. A. O. R.; CARVALHO, R. A. de. Escola e família no jornal O Arquidiocesano de Mariana...

(continuação)

\begin{tabular}{|c|c|c|c|c|c|}
\hline Ed. & Ano & Data & Pág. & $\begin{array}{l}\text { Notícias publicadas com tema } \\
\text { Escola }\end{array}$ & Autor \\
\hline 854 & 1976 & $25 / \mathrm{jan}$ & Capa & $\begin{array}{l}\text { Reg. do Ensino Religioso nas } \\
\text { Escolas Estaduais de } 1^{\circ} \text { e } 2^{\circ} \text { grau, } \\
\text { Portaria da Sec. da Edu. de } 13 \text { de } \\
\text { jan. (M. Gerais } 14 / 01 / 76 \text {, pg } 9 \text {, } \\
\text { col 03) }\end{array}$ & $\begin{array}{l}\text { Super. Edu. em Belo } \\
\text { Horizonte. Olavo Celso } \\
\text { Romano }\end{array}$ \\
\hline 868 & 1976 & $02 / \mathrm{mai}$ & 4 & $\begin{array}{l}\text { Escola Estadual D. Silvério. } \\
10 \text { Anos Educando (notícia } \\
\text { homenageando a escola) }\end{array}$ & Cônego Paulo Dilascio \\
\hline 889 & 1976 & $26 /$ set & 4 & $\begin{array}{l}\text { A Orientação da Catequese nas } \\
\text { Escolas (Recomendações do ensino } \\
\text { religiosos nas escolas) }\end{array}$ & $\begin{array}{l}\text { Mons. Abílio Real } \\
\text { Martins }\end{array}$ \\
\hline 908 & 1977 & $06 /$ fev & 2 & $\begin{array}{l}\text { Atraso Escolar (Matéria que trata } \\
\text { do desajuste entre idade e série) }\end{array}$ & $\begin{array}{l}\text { Estado de Minas, } \\
18 / 01 / 77\end{array}$ \\
\hline 934 & 1977 & 07/ago & 4 & $\begin{array}{l}\text { Educação Religiosa nas Escolas } \\
\text { Oficiais (Trata do Papel da escola } \\
\text { no ensino religioso) }\end{array}$ & ANI \\
\hline 934 & 1977 & 07/ago & 2 & A Educação Sexual nas Escolas & Gabriel dos Anjos \\
\hline 937 & 1977 & 28/ago & & A Escola Católica. Roma 1977a & $\begin{array}{l}\text { Sagrada Cong. para a } \\
\text { Educação Católica }\end{array}$ \\
\hline 938 & 1977 & $04 /$ set & 2 & $\begin{array}{l}\text { A Escola Católica. Roma 1977b - II } \\
\text { Problemática da Escola Católica }\end{array}$ & $\begin{array}{l}\text { Sagrada Cong. para a } \\
\text { Educação Católica }\end{array}$ \\
\hline 939 & 1977 & $11 /$ set & 2 & $\begin{array}{l}\text { A Escola Católica. Roma } 1977 \text { c - III } \\
\text { A Escola lugar de humanização } \\
\text { mediante a assimilação sistemática } \\
\text { e crítica da cultura }\end{array}$ & $\begin{array}{l}\text { Sagrada Cong. para a } \\
\text { Educação Católica }\end{array}$ \\
\hline 940 & 1977 & $18 /$ set & 2 & $\begin{array}{l}\text { A Escola Católica. Roma 1977d - } \\
\text { IV O Projeto Educativo da Escola } \\
\text { Católica }\end{array}$ & $\begin{array}{l}\text { Sagrada Cong. para a } \\
\text { Educação Católica }\end{array}$ \\
\hline 941 & 1977 & $25 /$ set & 2 & $\begin{array}{l}\text { A Escola Católica. Roma 1977e } \\
\text { - V Responsabilidade da Escola } \\
\text { Católica Hoje }\end{array}$ & $\begin{array}{l}\text { Sagrada Cong. para a } \\
\text { Educação Católica }\end{array}$ \\
\hline 942 & 1977 & $02 /$ out & 2 & $\begin{array}{l}\text { A Escola Católica. Roma 1977f - } \\
\text { VI Linhas de Ação }\end{array}$ & $\begin{array}{l}\text { Sagrada Cong. para a } \\
\text { Educação Católica }\end{array}$ \\
\hline 943 & 1977 & 09/out & 2 & $\begin{array}{l}\text { A Escola Católica. Roma } 1977 \mathrm{~g} \\
\text { - VII Conclusão - Empenho } \\
\text { Corajoso e Solidário }\end{array}$ & $\begin{array}{l}\text { Sagrada Cong. para a } \\
\text { Educação Católica }\end{array}$ \\
\hline 976 & 1978 & 04/jun & 2 & Leitura nas Escolas & José Clemente \\
\hline 990 & 1978 & $10 /$ set & 2 & Grego e Latim voltam à Escola & ANI \\
\hline
\end{tabular}

(continua) 


\begin{tabular}{|c|c|c|c|l|l|}
\hline Ed. & Ano & Data & Pág. & $\begin{array}{l}\text { Notícias publicadas com tema } \\
\text { Escola }\end{array}$ & \multicolumn{1}{c|}{ Autor } \\
\hline 1053 & 1979 & $18 /$ nov & Capa & Os Pais e a escola primária & Dom Oscar de Oliveira \\
\hline 1109 & 1980 & $14 /$ dez & 4 & $\begin{array}{l}\text { Secretário da Educação do Rio } \\
\text { defende a volta de disciplina } \\
\text { escolar }\end{array}$ & $\begin{array}{l}\text { Estado de Minas, } \\
13 / 11 / 80\end{array}$ \\
\hline 1125 & 1981 & $05 /$ abr & Capa & $\begin{array}{l}\text { Ensino Religioso nas escolas do } \\
\text { Estado }\end{array}$ & Dom Oscar de Oliveira \\
\hline 1126 & 1981 & $12 /$ abr & Capa & $\begin{array}{l}\text { Ensino Religioso nas escolas do } \\
\text { Estado II }\end{array}$ & Dom Oscar de Oliveira \\
\hline 1126 & 1981 & $12 /$ abr & 2 & Ensino Religioso na Escola & ANI \\
\hline 1228 & 1983 & $27 /$ mar & 2 & $\begin{array}{l}\text { Coordenação da Pastoral Ensino } \\
\text { Religioso nas Escolas }\end{array}$ & Pe. Paulo Dilascio \\
\hline 1250 & 1983 & $28 /$ ago & 4 & $\begin{array}{l}\text { ICHS Lança livro sobre educação: } \\
\text { Escola, Saber e Vida (Prefácio da } \\
\text { Obra) }\end{array}$ & $\begin{array}{l}\text { Côn. José G. V. de } \\
\text { Carvalho }\end{array}$ \\
\hline 1266 & 1983 & $18 /$ dez & 4 & Ensino Religioso nas Escolas & Cônego Paulo Dilascio \\
\hline 1440 & 1987 & $28 /$ abr & 3 & $\begin{array}{l}\text { Constituição, Educação e Ensino } \\
\text { Religioso (Grupo de Apoio ao } \\
\text { Ensino Religioso Escolar do R. G. } \\
\text { do Sul...) }\end{array}$ & ANI \\
\hline 1425 & 1987 & $11 /$ jan & Capa do Problema vivido pelas & $\begin{array}{l}\text { Escolas Públicas e Escolas } \\
\text { Católicas }\end{array}$ & ANI \\
\hline 1567 & 1989 & $08 /$ out & Capa & $\begin{array}{l}\text { Escolas particulares) } \\
\text { Escola Família }\end{array}$ & $\begin{array}{l}\text { Dom Luciano M. de } \\
\text { Almeida }\end{array}$ \\
\hline
\end{tabular}

FONTE: O Arquidiocesano (1962-1989). Elaboração das autoras.

O enfoque dos artigos é a escola primária. Vale lembrar que o público alvo da missão católica, por excelência, é a criança seguida da juventude, como defende especificamente Dom Oscar de Oliveira na matéria Em prol da escola primária (OLIVEIRA, 1970, capa). Os conteúdos escolares do jornal, assinados em sua maioria por Dom Oscar de Oliveira, estão marcados pela preocupação com a escola pública católica e contrastam com temas diversificados que vão desde educação sexual, a volta do grego e do latim nas escolas até as normativas educacionais. A manutenção da fé católica nas escolas é um tema caro à ordem com histórico de tensão e resistência na legislação educacional do país, confirmado pela matéria Liberdade de Ensino, 
a qual expõe o documento redigido pelo Movimento Pró Liberdade de Ensino apoiado pela igreja (LIBERDADE..., 1960, p. 2).

O primado da Igreja no campo educacional escolar foi tema tratado por Dom Oscar de Oliveira em palestra proferida na sede do Instituto Histórico e Geográfico de Minas Gerais (IHGB-MG), em 19 de dezembro de 1974, do qual era associado (OLIVEIRA, 1975, p. 3). O jornal publicou um resumo da fala com o título A Igreja, criadora das primeiras escolas primárias em Minas Gerais. Na ocasião, Dom Oscar fez questão de "citar nomes pioneiros de mestres de meninos em várias regiões da capitania", tendo como fonte as Provisões e Portarias da Cúria Diocesana, a partir de 1749, para enfatizar a relação da Igreja com o fortalecimento da escola brasileira (OLIVEIRA, 1975, p. 3). Informa, ainda, que a Igreja também se ocupou da educação das meninas citando o Convento de Macaúbas, criado no segundo quartel do século XVIII, primeira escola para meninas na Capitania de Minas Gerais. Um dos estudos sobre esse convento foi feito por Ana Cristina Pereira Lage (2019). O segundo educandário feminino foi criado em Mariana, a Casa da Providência, em abril de 1849 (OLIVEIRA, 1975, p. 3).

Excertos do documento da Santa Sé intitulado A Escola Católica, de autoria da Sagrada Congregação para a Educação Católica, de 19 de março de 1977, foram publicados semanalmente no jornal entre os dias 28 de agosto e 9 de outubro do mesmo ano somando sete artigos com os seguintes subtítulos: A escola católica (SAGRADA..., 1977b, p. 2); Problemática da Escola Católica (SAGRADA..., 1977c, p. 2); A Escola lugar de humanização mediante a assimilação sistemática e crítica da cultura (SAGRADA..., 1977d, p. 2); O Projeto Educativo da Escola Católica (SAGRADA..., 1977e, p. 2-3); Responsabilidade da Escola Católica Hoje (SAGRADA..., 1977f, p. 2); Linhas de Ação (SAGRADA..., 1977g, p. 2); Empenho Corajoso e Solidário (SAGRADA..., 1977h, p. 2). O documento foi inspirado na Declaração Gravissimum educationis emitida pelo Papa Paulo VI em outubro de 1965. Sobre essa Declaração, o jornal publicou, entre 1967 e 1968, quatro artigos assinados por Dom Oscar de Oliveira.

O primeiro artigo, intitulado Introdução, discorre sobre a natureza e as características de uma Escola Católica tendo em vista sua atuação em diversos contextos e países, submetida a distintas legislações. Ao ressaltar o valor educativo do pensamento cristão, propõe-se a colaborar na elaboração de um projeto educativo que atenda às exigências de uma educação integral:

A S. Congregação faz também apelo a todos os responsáveis pela educação - pais, professores, autoridades escolares - para que reúnam todos os recursos e meios disponíveis que permitam à Escola Católica 
exercer um serviço realmente cívico e apostólico (SAGRADA..., 1977a, grifo do autor).

Apontando o pluralismo cultural como a característica mais marcante da sociedade da época, na mesma matéria, destaca o dever educativo da Igreja de "garantir a presença do pensamento cristão". Além do pluralismo cultural listam "o materialismo, o pragmatismo, o tecnicismo" frente aos quais há que potencializar recursos educativos da instituição. Em contrapartida ao pluralismo cultural, o texto

defende o princípio do pluralismo escolar, ou seja, a coexistência e, se for possível, a cooperação entre as diversas instituições escolares, que permitam aos jovens formar critérios de avaliação fundados numa concepção específica do mundo, prepararem-se para participar ativamente na construção de uma comunidade e, por meio dela, na construção da sociedade (SAGRADA..., 1977a).

Porém, o pluralismo escolar, ou mesmo a liberdade de ensino como propalada no excerto acima, inspira suspeitas ou, no mínimo, questionamentos quanto à sua aplicação. Ao oferecer a alternativa do pluralismo escolar, a Igreja pretende contribuir "para promover a liberdade de ensino, de modo que se tutele e garanta a liberdade de consciência e o direito dos pais de escolherem a escola que melhor corresponda aos seus propósitos educativos" porque "a ausência da Escola Católica constituiria uma perda imensa para a civilização, para o homem e para os seus destinos naturais e sobrenaturais" (SAGRADA..., 1977a). Em suma, promover a liberdade de ensino diz respeito à hegemonia do catolicismo na sociedade mineira e à livre escolha da família pela escola dos filhos.

Pode-se perceber certa estratégia da Igreja em se colocar atenta ao que acontecia no campo educacional. Neste sentido, o periódico não se furtou de anunciar e criticar a publicação do livro de Manuel Bergstrom Lourenço Filho (1967), "Introdução ao estudo da Escola Nova”, pela Editora Melhoramentos. Segundo o periódico,

Em fins da década de vinte, o autor, iniciava a reformulação de novos métodos educativos, mostrando os avanços da pedagogia no estrangeiro e 
como esse avanço deveria ser aplicado à realidade brasileira. Esse trabalho clássico, com sucessivos acréscimos desde o seu lançamento, sai agora completado e renovado, em 9a. edição. Uma suma da pedagogia moderna (ESCOLA NOVA, 1968, capa) [O Arquidiocesano].

Na acepção de Dom Oscar, o escolanovismo não era tão novo quanto se propagandeava. Afirma ele que a escola ativa foi, primeiramente, apresentada por Santo Tomás de Aquino, no século XIII. No ideário aquiniano, o combate à passividade na educação, muito menos aceitável quando se tratasse de educação de adolescentes e jovens, era assunto primordial.

Esta chamada escola nova, entretanto, é muito antiga; remonta a muitos séculos. Com efeito, já Santo Tomás de Aquino, no século XIII, discutindo a questão da aprendizagem, combatia a passividade em educação. Demonstrou ele que não pode haver educação sem participação ativa do aluno, pois a causa eficiente principal da aprendizagem não é o professor, mas o próprio aluno (ESCOLA NOVA, 1968, capa) [O Arquidiocesano].

$\mathrm{Na}$ esteira dos ataques às escolas públicas, nas páginas do jornal encontra-se a matéria intitulada Escola da lata de lixo (ESCOLA..., 1969, p. 4) [O Arquidiocesano]. O sugestivo título pode fazer menção ao fato de que, coincidentemente, em Mariana, em meados da década de 1960 abriu-se uma escola que ganhou o apelido, carinhoso, de Escola de Lata. Eram tempos difíceis no tocante às verbas para a educação e o governo insistia em abrir escolas mesmo sem as mínimas condições de trabalho. Neste caso, a escola funcionava em um galpão, daí o apelido. No entanto, Escola da lata de lixo, diz respeito também às "doutrinações e estímulos peçonhentos" emanados de livros, jornais, revistas em quadrinhos, cujo tema principal é o sexo e "todo o gênero de pornografias". $\mathrm{O}$ artigo discorre sobre o assunto, exaltando sua posição contrária à escola $\mathrm{e}$ conclama às famílias cristãs a elevarem sua "voz de protesto" a "essas misérias que estão solapando a família - base e fundamento da sociedade. A sociedade será o que for a família" (ESCOLA..., 1969, p. 4) [O Arquidiocesano]. Se "a sociedade será o que for a família", faz sentido apreender a relação entre família, escola e igreja católica. 


\section{Relação família e escola nas páginas de O Arquidiocesano}

À família se atribui papel central na missão de desenvolver o indivíduo, pois, "educar é obra da família", afirma o artigo Escola, extensão da família, replicado do jornal Diário de Notícias, de Ribeirão Preto (ESCOLA..., 1963, p. 3). O lar é o principal aliado do trabalho escolar na formação das novas gerações. Na matéria supracitada afirma-se que as competências dos pais vão para além da criação dos/as filhos e filhas, isto é, os pais são responsáveis também pelo desenvolvimento do espírito da criança.

Em caso de a família falhar nessa missão, ela encontra no Estado seu aliado mas, somente, em caráter supletivo, fiscalizador de força soberana e moderadora que é. A falha em questão diz respeito à não possibilidade de os pais manterem a escola privada católica para seus filhos, conforme destaca o Diário de Notícias "a escola do Estado deve existir onde não pode existir escola particular em que os educadores são verdadeiramente os delegados de confiança dos pais de família. É somente assim.” (ESCOLA..., 1963, p. 3).

A visão de Estado como suplente educativo demonstra que $O$ Arquidiocesano defende a livre iniciativa e a disputa pelo mercado escolar. Significa dizer que a escola pública seria opção às famílias católicas que não pudessem arcar com o peso da formação do caráter de seus filhos no seio das escolas sob a administração e orientação da Igreja Católica. $\mathrm{O}$ apoio à livre iniciativa, ao direito das famílias escolherem a educação que quiserem para os filhos e a quebra do monopólio do Estado sobre o processo de escolarização constam da LDB 4.024/1961 (BRASIL, 1961), no título II, Do direito à educação, artigos $2^{\circ}$ e $3^{\circ}$. A normativa legal resguarda acordos entre o Estado e a Igreja Católica quanto ao entendimento de livre concorrência entre escolas públicas e privadas a gosto das famílias.

As matérias Família, escola basilar e Escola e Família, assinadas por Dom Oscar de Oliveira em edições seguidas no ano de 1968, confirmam o entendimento acerca da posição da família frente à sociedade como "a primeira escola de formação do homem. Primeira e insubstituível" e "a escola deve ser encarada como o complemento da educação familiar" (OLIVEIRA, 1968, capa). Neste sentido, nota-se o princípio fundante da escola enquanto extensão da família e a preocupação do clero em administrar um corte nos preceitos católicos familiares se a escola não estiver alinhada à mesma missão religiosa.

Uma forma de se posicionar a família na obra religiosa está no acompanhamento ao dever de casa. Destaca-se, assim, o artigo escrito pela colaboradora Myriam, em 05 de maio de 1968, intitulado Verificação dos trabalhos escolares dos filhos (MYRIAM, 1968, p. 3). A colaboradora orienta 
o dever de casa e a condução dos pais, reforçando o interesse do periódico de adentrar a vida privada dos fiéis.

Pode-se inferir que ao replicar a matéria do Diário de Notícias de Ribeirão Preto (SP), O Arquidiocesano entende por complemento a continuidade da educação católica transmitida no âmbito familiar, portanto, defende que a escola, pública ou privada, se adeque aos serviços sociais educacionais prestados às famílias. Com isso, delineia-se o conjunto harmonioso entre instituições da sociedade sob o manto da Igreja Católica. Como manter em harmonia constante as relações entre família, escola e igreja católica? O sucesso depende do trabalho do/a professor/a na escola.

\section{Professora católica: elo central da tríade família, escola e igreja}

Haveria que se pensar em manter as relações família e escola em sintonia levando-se em conta que ambas as instituições professam a fé católica. Quem senão a professora para manter os preceitos em vigor? Dom Oscar de Oliveira deixa claro em Escola e Família uma preocupação e uma solução. A preocupação diz respeito ao fato de "sem ligação entre família e escola não pode haver êxito completo na formação das novas gerações. Portanto hão de ser harmonicamente conjugados os esforços de pais e mestres na formação das crianças e dos adolescentes" (OLIVEIRA, 1968, capa). A solução, nas palavras de Dom Oscar, vem pela Associação de Pais e Mestres (APM). Em encontros periódicos, pais e mestres podem corrigir "falhas de parte a parte", afinal, os pais podem dar a conhecer melhor os filhos aos professores, "seus discípulos" e os professores podem oferecer aos pais "informes sobre seus filhos, de interesse educacional". $\mathrm{O}$ artigo aponta que "muitos pais, infelizmente, não dão o merecido apreço à Associação de Pais e Mestres" (OLIVEIRA, 1968, capa) por não consideraremna verdadeiro investimento.

Dom Oscar de Oliveira voltaria a falar sobre a APM na Escola Normal de Itabirito, em 1969, durante o discurso às formandas normalistas. Na ocasião, Dom Oscar reforça o objetivo da Associação de acompanhar a escola, ou seja, a "obra escolar toda, mas sobretudo a educação moral que nela deve administrar-se", enquanto preceito afirmado pelo Concílio Vaticano II, Gravissimum Educationis $\mathrm{n}^{\circ}$ 6. No artigo Às beneméritas Professoras das Escolas Primárias, o Arcebispo evoca os "princípios morais de virtudes cristãs" das professoras como algo que deve "penetrar fundo as almas infantis". A relação família, escola e professora aparece cingida de máximas e preceitos que reforçam o interesse cristão em 
ter na escola a aliada da egrégia missão, responsável pela formação humana, para a qual o tratamento nem sempre se faz com justiça. Ainda tratando das professoras, no subtítulo Formação integral, encontra-se que "A verdadeira pedagogia não se reduz apenas à cultura. Ela é basicamente educacional [...]" (OLIVEIRA, 1969, capa) e como a criança atua por meio da imitação, cabe aos adultos e à professora, especialmente, o exemplo de probidade moral e da prática das virtudes cristãs.

\section{(In)Conclusões}

O trabalho apresenta estudos a partir do semanário O Arquidiocesano, periódico da Arquidiocese de Mariana (MG), que circulou pelas paróquias da Região dos Inconfidentes de 1959 a 1991 com tiragem aproximada de 6.000 exemplares por ano. Dos objetivos do jornal constam o de "cuidar da vida religiosa das Paróquias". Com isso, o periódico adentrou os campos sociais incluindo a escola. Ao longo das edições é possível perceber a educação como tema recorrente no que tange à formação cristã como, por exemplo, a preocupação com a chegada da televisão no interior dos lares e a campanha contra o comunismo. Os artigos eram assinados, invariavelmente, por membros da hierarquia da Igreja ou paroquianos convidados. Por vezes reproduziam artigos publicados em outros impressos católicos. O corpus de pesquisa são as edições que tratam da educação escolar. Selecionamos os artigos que abordam a escola e a família, os quais tiveram seus conteúdos analisados para efeito de categorização, e destacamos a visão da igreja sobre a instituição escolar como colaboradora na formação humana.

A partir daí pudemos identificar que os artigos atestam a importância da escola como espaço social. Como locus da prática social, a escola primária, de preferência a de caráter confessional, é fundamental para a difusão dos princípios cristãos e, com isso, a Igreja se mostra em atualização constante em relação ao que vai se fazendo nesse ambiente. Entretanto, ainda que atualizada em matéria do social, fica claro que não há moral para além da moral cristã e a escola primária acaba por reafirmar o primado jesuítico de inculcação na infância dos princípios que se querem vislumbrar no adulto. Em consonância, se o futuro da criança é cristão, faz sentido a escolha dos pais pela escola católica guiada pela professora na mesma fé. 
É interessante notar o discurso da Igreja a favor da quebra de monopólio educativo do Estado pela livre concorrência privada. Isso porque a escola é complemento da educação familiar. Fica clara a equação: família cristã é igual a escola cristã. Se a escola é pública, torna-se tênue o controle da Igreja. Nessa circunstância, a professora sobressai como elemento fundamental para a preservação do discurso religioso. Assim, à escola pública, com professoras católicas, poderia ser confiada a formação da moral da infância.

Podemos finalizar com a assertiva de que $O$ Arquidiocesano vela pela população católica para além do espaço físico das igrejas ou dos sermões por meio do controle da tríade família, escola e professora.

\section{REFERÊNCIAS}

ADORNO, Sérgio. Os aprendizes do poder. Rio de Janeiro: Paz e Terra, 1988.

BASTOS, Maria Helena Câmara. Espelho de papel. In: ARAÚJO, José Carlos Souza; GATTI JUNIOR, Décio (org.). Novos temas em história da educação brasileira. Uberlândia: EDUFU, 2002. p. 151-174.

BICCAS, Maurilane. O impresso como estratégia de formação: Revista do Ensino de Minas Gerais (1925-1940). Belo Horizonte: Argumentum, 2008.

BRASIL. Câmara dos Deputados. Lei $N^{o}$ 4.024, de 20 de dezembro de 1961. Fixa as Diretrizes e Bases da Educação Nacional. Brasília, DF: Câmara dos Deputados, 20 dez. 1961. Disponível em: https://www2.camara.leg.br/legin/fed/lei/1960-1969/lei-402420-dezembro-1961-353722-publicacaooriginal-1-pl.html. Acesso em: 20 maio 2021.

ESCOLA da lata de lixo. O Arquidiocesano, Mariana, MG, p. 4, 19 jan. 1969.

ESCOLA NOVA. O Arquidiocesano, capa, 19 jan. 1969.

FREYRE, Gilberto. Ordem e Progresso. São Paulo: Global, 2013.

JESUS, Raquel Evangelista de. A Educação Moral e Cívica nos tempos da ditadura civil-militar (Mariana-MG 1969-1975). 2018. Dissertação (Mestrado em Educação) Universidade Federal de Ouro Preto, Ouro Preto, 2018.

LAGE, Ana Cristina Pereira. Religião Católica e instituições educativas na capitania de Minas Gerais. In: FONSECA, Thaís Nívia de Lima e; CARVALHO, Carlos Henrique de; FARIA FILHO, Luciano Mendes de (org.). História da Educação em Minas Gerais: da Colônia à República. Uberlândia: EDUFU, 2019. v. 1, p. 131-152.

LIBERDADE de Ensino. O Arquidiocesano, Mariana, MG, p. 2, 6 mar. 1960. 
LIMA, Gabriela Pereira da Cunha. Educação nos tempos de chumbo: uma visão do pensamento conservador católico através das páginas do jornal O Arquidiocesano. 2011. Monografia (Especialização em Teorias e Métodos de Pesquisa em Educação) Universidade Federal de Ouro Preto, Ouro Preto, 2011.

LOURENÇO FILHO, Manuel Bergstrom. Introdução ao estudo da Escola Nova. São Paulo: Melhoramentos, 1967.

MAGAlHÃES, Basílio da Gama. A escola. O Arquidiocesano, Mariana, MG, capa, 1 jul. 1962.

MYRIAM. Verificação dos trabalhos escolares dos filhos. O Arquidiocesano, Mariana, MG, p. 3, 05 maio 1968.

OLIVEIRA, (Dom) Oscar. Razão dêste Jornal. O Arquidiocesano, Mariana, MG, capa, 29 de jun. 1959.

OLIVEIRA, (Dom) Oscar. Educação da Juventude. O Arquidiocesano, Mariana, MG, p. 4,15 set. 1963 .

OLIVEIRA, (Dom) Oscar. Escola e família. O Arquidiocesano, Mariana, MG, capa, 03 mar. 1968.

OLIVEIRA, (Dom) Oscar. Às Beneméritas Professoras das Escolas Primárias. O Arquidiocesano, Mariana, MG, capa, 19 jan. 1969.

OLIVEIRA, (Dom) Oscar. Em prol da escola primária. O Arquidiocesano, Mariana, MG, p. 1,15 set. 1970.

OLIVEIRA, (Dom) Oscar. A Igreja, criadora das primeiras escolas primárias em Minas Gerais. O Arquidiocesano, Mariana, MG, p. 3, 9 nov. 1975.

SAGRADA Congregação Católica para a Educação. A Escola Católica. 1977a. Disponível em: http:/www.vatican.va/roman_curia//congregations/ccatheduc/documents/rc_con ccatheduc_doc_19770319_catholic-school_po.html. Acesso em: 13 set. 2020.

SAGRADA Congregação Católica para a Educação. A escola católica. O Arquidiocesano, Mariana, MG, p. 2, 28 ago. 1977b.

SAGRADA Congregação Católica para a Educação. Problemática da Escola Católica. O Arquidiocesano, Mariana, MG, p. 2, 04 set. 1977c.

SAGRADA Congregação Católica para a Educação. A Escola lugar de humanização mediante a assimilação sistemática e crítica da cultura. O Arquidiocesano, Mariana, MG, p. 2, 11 set. 1977 d.

SAGRADA Congregação Católica para a Educação. O Projeto Educativo da Escola Católica. O Arquidiocesano, Mariana, MG, p. 2-3, 18 set. 1977e.

SAGRADA Congregação Católica para a Educação. Responsabilidade da Escola Católica Hoje. O Arquidiocesano, Mariana, MG, p. 3, 25 set. $1977 \mathrm{f}$. 
SAGRADA Congregação Católica para a Educação. Linhas de Ação. O Arquidiocesano, Mariana, MG, p. 2, 02 out. $1977 \mathrm{~g}$.

SAGRADA Congregação Católica para a Educação. Empenho Corajoso e Solidário. $O$ Arquidiocesano, Mariana, MG, p. 2, 09 out. 1977h.

SILVA, (Pe.) Belchior Cornélio da Silva. O Arquidiocesano, Mariana, MG, p. 4, 6 set. 1959.

VENÂNCIO FILHO, Francisco. Fontes para a história da educação no Brasil. Revista Brasileira de Estudos Pedagógicos, Rio de Janeiro, v. 5, p. 369-374, 1945.

VIEIRA, Carlos Eduardo. Jornal diário como fonte e como tema para a pesquisa em História da Educação: um estudo da relação entre imprensa, intelectuais e modernidade nos anos de 1920. In: OLIVEIRA, Marcus Aurélio Taborda de (org.). Cinco estudos em História e Historiografia da Educação. Belo Horizonte: Autêntica, 2007. p. 11-40.

Texto recebido em 24/11/2020.

Texto aprovado em 25/04/2021. 